\title{
Inhalation Powder, Tablet Dosage Form
}

National Cancer Institute

\section{Source}

National Cancer Institute. Inhalation Powder, Tablet Dosage Form. NCI Thesaurus. Code C149581.

Solid multidose preparation intended for inhalation use. The dose of inhalation powder is generated from the tablet by a metering mechanism within the inhaler, for example by scraping off a small amount of powder from the tablet. 